\title{
Finite element analysis of stuffing-box packing subjected to thermo-mechanical loads
}

\author{
Kaoutar BAHOUM ${ }^{1}$, Mohammed DIANY ${ }^{2}$, Mustapha MABROUKI ${ }^{3}$
}

\begin{abstract}
The principal rule for the stuffing-box packings is to ensure the stem valve sealing. The behavior of these systems is affected by the operating conditions, which are the gland axial stress, the temperature, and the fluid pressure, as well as the mechanical and geometrical characteristics of the various components. In this paper, a numerical study using finite element method is presented to analyze the stresses and the displacements in a stuffing box system under the gland stress and the temperature field.
\end{abstract}

Keywords - Stuffing box, temperature, gland stress, finite element method.

\section{Introduction}

The packed stuffing-boxes are the most sealing systems used in the industrial installations. Their role is to ensure sealing of stem-valve, piston pins and actuators. They stop the fluid confined inside an equipment to escape to outside. Braided packing rings, made from deformable and relatively incompressible materials, are compressed to perform this sealing function. The malfunctioning of these assemblies can cause the considerable damage on the environment and in some cases life losses.

The braided gaskets are compressed by the gland between the stem and the housing, as shown in Fig.1.

The application of optimum gland axial stress, which generates contact pressures at packing-housing and at the stem-packing surfaces, is required to ensure the effectiveness and efficiency of the confinement. The confinement of fluid is also, affected during operation by temperature. The transfer of heat from the confined fluid to the components of the assembly has not yet been integrated into the design and modeling of gland assemblies with braided seals.

\section{Background}

The stresses distribution in stuffing-box systems attracted considerable attention from researchers over the past few decades. Pengyun et al. [1] presented a theoretical analysis to evaluate the ratio between the lateral pressure coefficient at the packing-stem interface to the one at the packing-housing interface. They obtained a relationship expressed in the term of the ratio of the friction coefficients and the packing dimensions as given by Eq. (1).

Kaoutar BAHOUM, Mohammed DIANY, Mustapha MABROUKI

University Sultan Moulay Slimane, Faculté des Sciences et Techniques, BP 523 Beni Mellal 23000, Beni Mellal

MOROCCO

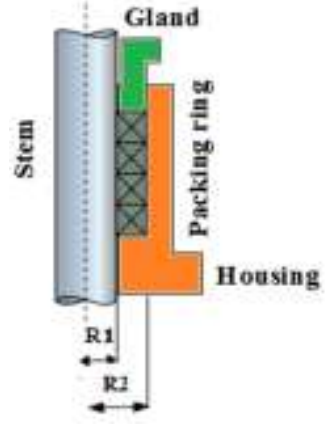

Figure 1: Stuffing-box system

$$
\frac{K_{i}}{K_{o}}=\left(\frac{\mu_{o}}{\mu_{i}}\right)\left(\frac{R_{2}}{R_{1}}\right)\left(\frac{3 R_{2}+5 R_{1}}{3 R_{2}+3 R_{1}}\right)
$$

The authors of the reference [1] validated their model with an experimental study.

Diany et al. [2] give Eq. (2) using a more precise calculation of the moments.

$$
\frac{K_{i}}{K_{o}}=\left(\frac{\mu_{o}}{\mu_{i}}\right)\left(\frac{R_{2}}{R_{1}}\right)\left(\frac{5 R_{2}+7 R_{1}}{7 R_{2}+5 R_{1}}\right)
$$

Diany et al. [3] proposed a simplified analytical approach using the thick-walled cylinder theory to study stresses and displacements of stuffing-box packing. They proved that the contact pressure ratio is close to one and that the interface contact pressure depends on several parameters such as the assembly geometry, friction and the mechanicals characteristics of the used materials. The same authors [4] developed a hybrid method to characterize the braided packing. Three-axial compression tests combined with finite element simulations were used to evaluate lateral pressure coefficients, elasticity modulus and Poisson's coefficient.

Kazeminia et al. [5-7] presented several analytical models to evaluate the stresses in the stuffing-box components. They presented a contact stress modeling study based on two configurations. The first configuration consists of introducing a variable gap between the packing and the housing, which induces a uniform distribution of the axial stress. The second configuration, which is more efficient, consists of inserting one ring of the gasket at a time and imposing plastic deformation via a loading and unloading process. Each time a new ring is put in place, it will be subjected to residual stresses. They also developed an analytical model based on the combination of ring theory, thin cylinder theory and beam on elastic foundation theory. The results of the analysis of flexible graphite subjected to three load cases were compared with results obtained by finite element analysis and experimental tests. 
Veiga et al. [8] and Girao et al. [9] presented experimental studies; they introduced a test device and a protocol for simulating a gland system. They evaluated the expansion of the packing under different temperatures. The axial pressures, at the bottom of the gland and at the gland, and the torque generated during the turning were measured to evaluate the influence of thermal expansion on these measurements. These tests show that the expansion of the packing due to temperature variations can considerably increase the internal stresses of the gland, leading to high torque, and contrarily during systems cool down the decrease of the gland pressure results in high leakage rates. The results also indicate that if the volumetric content of PTEE is higher, it increases the gland stress and the leakage control becomes more difficult.

The purpose of this work is to evaluate the effect of the confined fluid temperature on the distribution of axial stress, contact pressures and displacements. This is done using the finite element method.

\section{Finite Element Analysis}

The behavior of the stuffing box packing system subjected to the combination of the gland pressure and the thermal load is evaluated by a finite element analysis model carried out using the ANSYS software [10].

\section{A. Finite element model}

An axisymmetric model is used to study the combined effect of the fluid temperature and the compression load on the axial distribution of the contact pressure, at the stem-packing and the packing-housing interfaces. Fig. 2 shows this model with the obtained oriented mesh. The 2D element with eight nodes, PLANE223, with four degrees of freedom per nodes (the three displacements and the temperature) is chosen for this study. The assembly components are in contact in the radial direction. Contact elements are used to simulate the reaction of the stuffing-box elements when they are in contact. The elements CONTA172 and TARGE169 are used. Materials characteristics

The mechanical properties of the Stuffing-box components affect the resulting stresses and displacements. In this study, the stem and the housing are made of ordinary steel and the

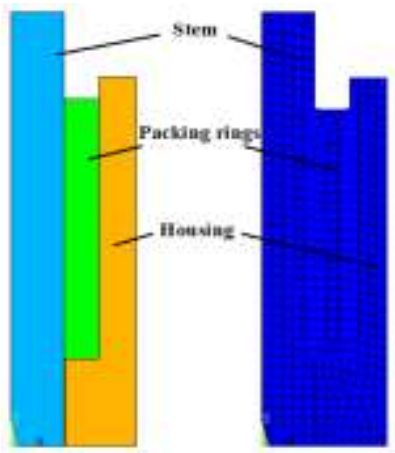

Figure 2: Finite Element model of stuffing box packing braided packing is made of Polytetrafluoroethylene (PTFE). Table 1 shows the mechanical and geometrical properties of the components of the assembly.

TABLE I. STUFfiNG-BOX COMPONENTS MATERIAL CHARACTERISTICS

\begin{tabular}{|l|l|l|l|}
\cline { 2 - 4 } \multicolumn{1}{c|}{} & \multicolumn{1}{c|}{ Stem } & Packing & Housing \\
\hline Inner radii $(\mathrm{mm})$ & - & 14.29 & 23.89 \\
\hline Outer radii $(\mathrm{mm})$ & 14.29 & 23.89 & 33.75 \\
\hline Young Modulus $(\mathrm{GPa})$ & 200 & 0.126 & 200 \\
\hline Poison's coefficient & 0.3 & 0.4 & 0.3 \\
\hline $\begin{array}{l}\text { Coefficient of thermal } \\
\text { expansion } \mathrm{K}^{-1}\end{array}$ & $11.6 \mathrm{e}-6$ & $126 \mathrm{e}-6$ & $11.6 \mathrm{e}-6$ \\
\hline
\end{tabular}

\section{B. Boundary conditions}

The boundary conditions must represent real operating conditions. Indeed, the upper surface of the packing is subjected to the uniform axial compression load applied by the gland. The lower surfaces of the housing and the stem are at a uniform high temperature, which is transferred from the confined fluid. The other outer surfaces are at room temperature. The displacements in the radial and axial directions are blocked at the bottom of the assembly.

The radial contact pressures as well as the axial displacements, under different temperature distributions are examined.

\section{Results and discussions}

To study the effect of the temperature of the fluid, which is in contact with the packing-box components, on the distribution of stresses and displacements, the axisymmetric model presented in the previous paragraph is implemented. Indeed, for an axial tightening pressure of $30 \mathrm{MPa}$, three values of the fluid temperature have been adopted and which reflect the actual operating temperature range of the stuffingbox packings.

Figure 3 shows the temperature distribution in the stuffingbox assembly when the fluid temperature is about $250{ }^{\circ} \mathrm{C}$. At the bottom of the housing, the temperature is imposed; it corresponds to the fluid one. The other walls of the system are at room temperature. The temperature decreases, moving
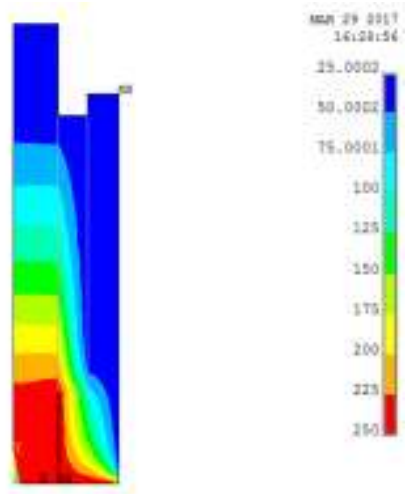

Figure 3: Distribution of temperature in stuffing box packing 


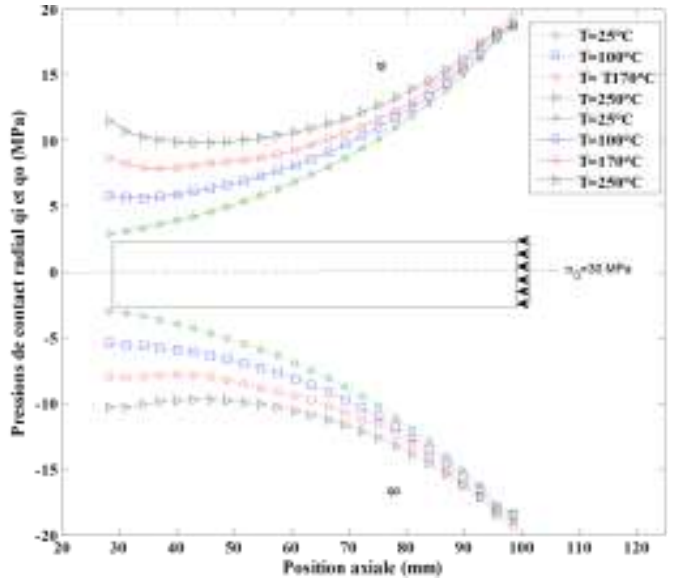

Figure 4: Distribution of radial contact stress

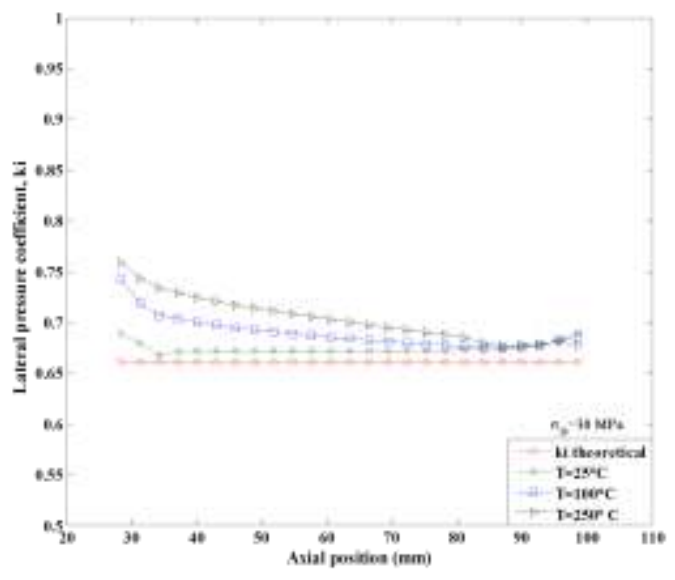

Figure 6: Lateral pressure coefficient $k_{i}$ towards the outer walls.

Figure 4 presents the distribution of the radial contact pressures, qi at the stem-packing interface and qo at the packing-housing interface. The curve's shape of these contact pressures is exponential. For the same thermal load and the same axial position, the contact pressures, qi and qo, have identical values. The compressive force is applied to the upper parking surface, which is always at room temperature. As a result, the contact pressures have the same value at this surface for all cases. This value is about $18 \mathrm{MPa}$. The contact pressures decrease as we approach the bottom of the packing. For the same axial position and far from the upper packing surface, the contact pressure increases in absolute value as the temperature of the fluid increases.

Figure 5 illustrates the effect of the temperature on the axial stresses distribution at the stem-packing interface, $\sigma_{x i}$, and at the interface packing-housing, $\sigma_{\mathrm{xo}}$. For a given axial position, if the fluid temperature increases, the stress increases. The variation of the axial stress is more significant for the inner packing surface; especially for $250{ }^{\circ} \mathrm{C}$.

Figures 6 and 7 show the lateral pressure coefficients; which represent the portion of the axial stress that changes to

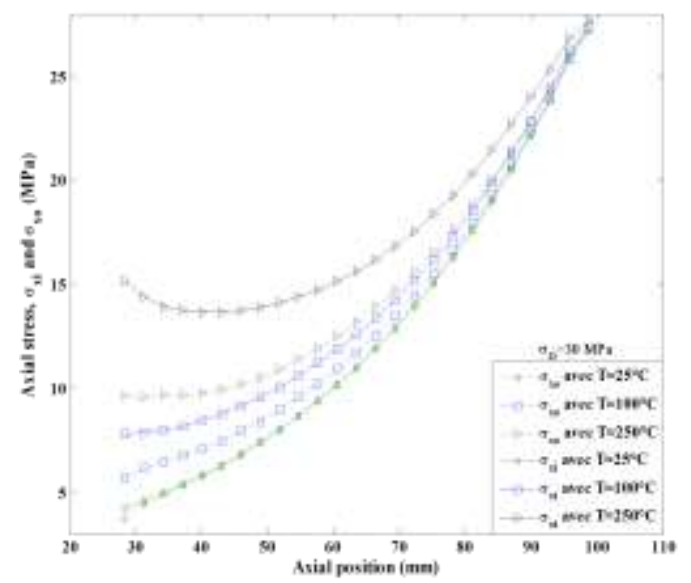

Figure 5: Distribution of axial stress contact pressure in the radial direction; at the stem-packing interface, ki, and at the packing-housing interface, ko, respectively. In Fig. 6, the shape of the curves is close to the curve of ki theoretically calculated by Diany et al [3]. Whereas in the case of Fig. 7, If the temperature exceeds $100^{\circ}$, the coefficient values tend to exceed 1 in the lower part of the packing. This is because of changes in the distribution of the axial stress.

The axial displacements at the inner interfaces of the braided packing are presented in Fig. 8. The value of displacements are equal to zero at the bottom of the packing and maximum at its top. The effect of the temperature increase attempts to reduce the axial displacement of the packing at the inner face while it is less significant for the displacement at the packing-housing interface, as presented in Fig. 9.

\section{v. Conclusion}

The finite element model of the gland assembly under the effect of temperature and tightening load is presented. The results of the elaborated numerical model show that if the temperature of the fluid confined inside varies, the axial and

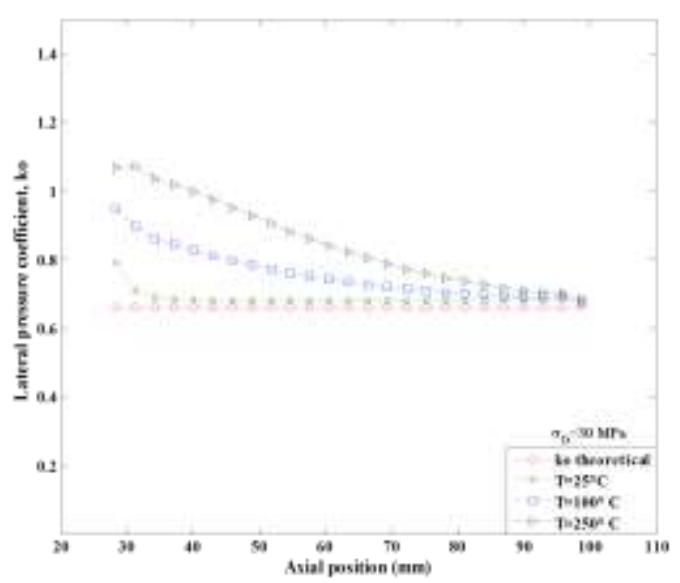

Figure 7: Lateral pressure coefficient $k_{o}$ 


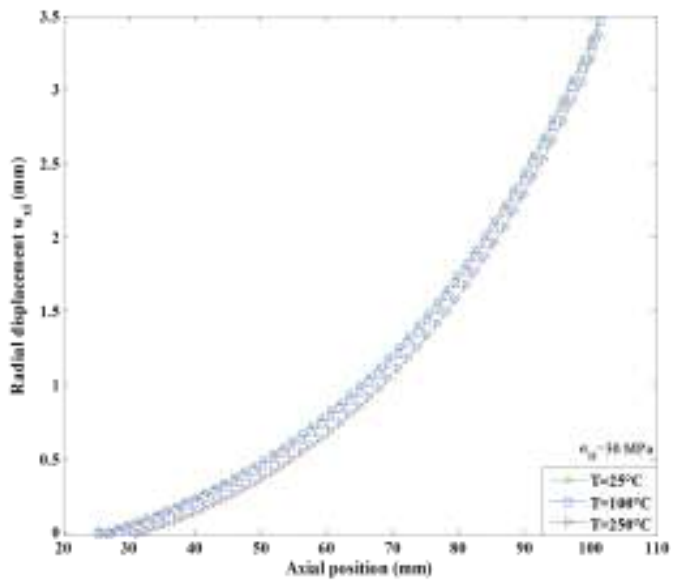

Figure 8: Axial displacement $w_{r i}$

radial displacements, the contact pressures and the lateral pressure coefficients vary accordingly. When the temperature of the fluid exceeds $100{ }^{\circ} \mathrm{C}$, the tightening stress must be adjusted to ensure leaktightness and thus efficiency and efficiency of the gland system.

\section{References}

[1] S. Pengyun, C. Kuangmin, and D. Zongyun, "A theoretical analysis of the lateral pressure coefficients in a soft-packed stuffing-box seal," Tribology International, vol. 30, no. 10, (1997). pp. 759-765.

[2] M. Diany, A,-H. Bouzid, "Evaluation of contact stress in stuffing box packing. In : 2006 ASME-PVP conference, paper no. PVP2006ICPVT11-93083, Vancouver, Britisg Columbia ; 2006.

[3] M. Diany and A.-H. Bouzid, "Analytical evaluation of stresses and displacements of stuffing-box packing based on a flexibility analysis," Tribology International, vol. 42, no. 6, (2009) pp. 980-986.

[4] M. Diany, and A. H. Bouzid, "An Experimental- Numerical Procedure for Stuffing Box Packing Characterization and Leak Tests," ASME J. Tribol, 133(1), (2011), p. 012201

[5] M. Kazeminia and A.-H. Bouzid, "Analysis of stresses and strains in packed stuffing-boxes," in Proceedings of the ASME Pressure Vessels and Piping Conference (PVP '14), Anaheim, Calif, USA, (2014) pp. 111.

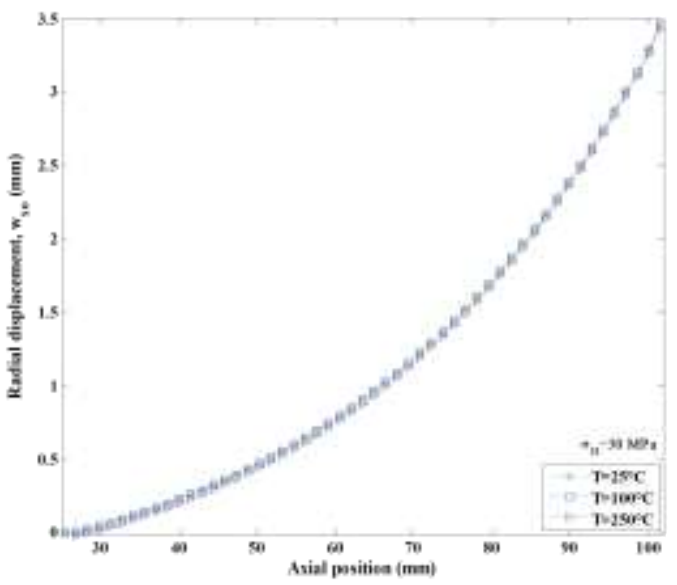

Figure 9: Axial displacement $w_{\text {ro }}$
[6] M. Kazeminia and A.-H. Bouzid, "Analytical and numerical evaluation of the axial stress distribution of two soft-packed stuffing-box configurations," in Proceedings of the ASME Turbo Expo 2014, Turbine Technical Conference and Exposition, D"usseldorf, Germany, 2014, pp. $1-8$.

[7] M. Kazeminia and A.-H. Bouzid, "Stress analysis of packed stuffingboxes," Journal of Pressure Vessel Technology, vol. 137, no.5, (2015) Article ID 051205

[8] J. C. Veiga, A. S. Carmo, C. D. Girao et al., "The influence on the stuffing box of the forces generated by packing thermal expansion," in Proceedings of the Pressure Vessels Piping Division Conference (ASME '11), Baltimore, Md, USA, July 2011. pp. 227-233,

[9] C.D. Girao and K.Guenther, "Evaluation of stuffing box forces associated with the thermal expansion of e-PTFE and graphite packing sets," in Proceedings of the ASME Pressure Vessels and Piping Conference, Toronto, Canada, July 2012, pp.167173

[10] Ansys. Standard Manuel. Version 17.1

About Author (s):

\begin{tabular}{|l|l|}
\hline & $\begin{array}{l}\text { Bahoum Kaoutar is currently a PhD student in the } \\
\text { laboratory of Industrial engineering in Faculty of } \\
\text { Science and Technics of Béni Mellal, Morocco. She } \\
\text { received her engineering degree in Industrial } \\
\text { engineering and Logistics from National School of } \\
\text { Applied Sciences - Marrakesh, Cadi Ayyad } \\
\text { University-Morocco. Her research focuses on } \\
\text { Mechanical engineering, structural mechanics and } \\
\text { material sciences. }\end{array}$ \\
\hline
\end{tabular}

